\title{
Cuidados de enfermagem ao cliente com peritoneostomia
}

\author{
Customer nursing care with peritoneostomy
}

\author{
Carlos Eduardo Peres Sampaio' • Ariane da Silva Pires²
}

Define-se peritoneostomia como uma técnica cirúrgica conhecida como "abdome aberto", que é um tratamento complexo e crucial, o qual consiste num procedimento de controle de danos nos casos de hipertensão intra-abdominal (HIA) e síndrome compartimental abdominal (SCA), além de peritonite supurativa severa. De acordo com a literatura mundial, o reconhecimento rápido e a laparotomia descompressiva são os melhores tratamentos para HIA e SCA pós-operatória ${ }^{(1)}$.

Nas Unidades de Terapia Intensiva (UTIs), a equipe depara-se, entre outras abordagens terapêuticas, com o tratamento aberto para abdome em estado séptico, o qual as considerações terapêuticas e prognósticas são bastante complicadas e com risco de os pacientes evoluírem para síndrome de disfunção múltipla de órgãos - SDMO(2).

$\mathrm{Na}$ prática assistencial, constata-se também que o enfermeiro, ao cuidar do paciente com peritoneostomia, encontra grandes desafios, sendo necessário aprimoramento técnico, fundamentação científica, uso e/ou elaboração de protocolos, a fim de proporcionar melhor assistência ao paciente, acelerando a sua reabilitação(2). Neste sentido, o cuidado de enfermagem no manejo da peritoneostomia deve ser fundamentado em conhecimentos diferenciados com o fato de proporcionar a devida assistência à beira do leito, monitorando, sinalizando e antevendo as perdas de fluídos e possíveis fístulas entero-atmosféricas ${ }^{(2)}$.

$\mathrm{Na}$ mesma perspectiva, faz-se relevante à prestação de cuidados especializados em Enfermagem em Dermatologia, visto que o fechamento precoce deste tipo de abordagem médica, facilitado por uma inovação tecnológica, utilizando a pressão negativa, tem o potencial de reduzir a complexidade de um abdome aberto ${ }^{(2)}$.

Cabe ressaltar que o direito a assistência à saúde é conferido por lei segundo a Portaria n. ${ }^{\circ} 479 / \mathrm{MS}$, de 15 de Abril de 1999, que enfatiza a importância do atendimento hospitalar na assistência ao paciente em situações de urgência e emergência, providenciando a peritoneostomia como um dos procedimentos disponíveis no sistema de saúde, ficando subentendidos como recursos tecnológicos e humanos acessíveis e de qualidade.

Os dados do Sistema Único de Saúde (DATASUS), no período de 2010 a 2012, constatou o número de óbitos decorrentes do tratamento de doenças do peritônio sendo estes 408 casos no Brasil. Na região sudeste há o maior número de casos em comparação as demais regiões brasileiras, sendo 244 casos, evidenciando a relevância desta problemática de saúde.

Assim sendo, faz-se necessário definir métodos estratégicos para a prestação eficaz da assistência de enfermagem, utilizando inovações tecnológicas que diminuam a morbimortalidade decorrente de tal problema. Inovações recentes forneceram uma variedade de técnicas para o fechamento permanente e temporário do abdome, resultando em vários benefícios e minimizando as complicações potenciais do abdome aberto(3).

O curativo com pressão negativa possibilita o controle da infecção, com diminuição do edema e exsudação, acelera consideravelmente o processo cicatricial e prepara em um tempo acelerado, a área lesionada para receber outra opção de terapia tópica ${ }^{(3)}$.

Os benefícios clínicos ao paciente com abdome aberto, que utiliza o curativo por pressão negativa, deve-se ao fato de aumentara média do tempo de fechamento, acelerando a cicatrização por meio da aplicação de uma camada não aderente que ajuda na proteção dos conteúdos abdominais. Ademais, essa tecnologia apresenta vantagens como:

'Enfermeiro. Doutor em Bioquímica Médica. Professor Associado do Departamento de Enfermagem Médico-Cirúrgica da Faculdade de Enfermagem de Enfermagem da Universidade do Estado do Rio de Janeiro. Professor Titular da Universidade Veiga de Almeida. Rio de Janeiro. RJ. Brasil. E-mail: carlosedusampa@ ig.com.br.Autor correspondente.

${ }^{2}$ Enfermeira. Mestre em Enfermagem. Docente do Departamento de Enfermagem Médico-Cirúrgica da Faculdade de Enfermagem da Universidade do Estado do Rio de Janeiro. Rio de Janeiro. RJ. Brasil.E-mail: arianepires@oi.com.br 
redução de contaminação e infecção, diminuição do número de trocas de curativos, drenagem eficaz do líquido e fluido visceral e possibilidade de mensuração do controle dos conteúdos abdominais ${ }^{(3)}$.

As evidências clínicas da eficácia do fechamento da peritoneostomia pelo uso da pressão negativa em comparação aos métodos convencionais é comprovada, pois tanto no fechamento temporário quanto no permanente, ela reduz a septicemia e a falência múltipla de órgãos ${ }^{(3)}$.

Conclui-se que a terapia por pressão negativa é uma inovação tecnológica com boa aplicabilidade na situação de peritoneostomia, utilizando-a como cobertura temporária da lesão cirúrgica. Ela permite o fechamento mais rápido da ferida abdominal, reduzo número de reoperações e confere proteção adequada das alças intestinais contra contaminação bacteriana. Além disso, diminui o ritmo de trabalho da enfermagem, uma vez que restringe as trocas dos curativos.

O trabalho multidisciplinar é imprescindível para o tratamento da pessoa com o abdômen aberto. Mas, faz-se necessário a visão holística do enfermeiro estomaterapeuta voltado para a rapidez da cicatrização, assim como a redução de custos hospitalares e a diminuição na taxa de mortalidade dos pacientes peritoneostomizados. Cabe ainda a elaboração e o uso de protocolos institucionalizados a fim de direcionar a assistência eficaz a beira do leito. 


\section{REFERÊNCIAS}

I.Malbrain MI. Intra-abdominal hypertension: evolving concepts. 3.Horwood J, Akbar F, Maw A. Initial experience of laparostomy Clin Chest Med. 2009; 30(1): 45:70.

2.Furtado P. Controle de danos em cirurgia. Rev. AMRIGS. $200 I ; 45(I, 2): 7 \mid-6$.

with immediate vacuum therapy in patients with severe peritonitis. Annals of the Royal College of Surgeons. 2009; 9I(8):68I-687. 